Anders Raustorp* and Andreas Fröberg

\title{
Comparing self-perceived global self-esteem and physical self-esteem among children and adolescents in Southeastern Sweden, investigated in 2000 and 2017
}

https://doi.org/10.1515/ijamh-2018-0250

Received September 4, 2018; accepted November 18, 2018;

published online June 8,2020

\section{Abstract}

Objectives: To compare self-perceived global self-esteem (GSE) and physical self-esteem (PSE) among children and adolescents aged 11 and 14 years in Southeastern Sweden, investigated in 2000 and 2017.

Methods: The present study consists of two independent cross-sectional study-cohorts from Southeastern Sweden, investigated in 2000 and 2017. The same protocol, procedures, and instruments were used in 2000 and 2017. In October 2000, data for self-perceived GSE and PSE, and anthropometry were collected from 11-years old children (Grade 5) ( $\mathrm{n}=74)$ and 14-years old adolescents (Grade 8) $(\mathrm{n}=84)$. In October 2017, children ( $\mathrm{n}=186)$ and adolescents $(\mathrm{n}=140)$ from the same grade-levels, schools and classrooms provided data for the same variables as in 2000. GSE and PSE were assessed with the Children and Youth Physical Self-Perception Profile (CY-PSPP).

Results: Self-perceived GSE was higher in 2017 as compared to 2000 among both 11-years old boys ( $\mathrm{p}<0.001)$ and girls $(\mathrm{p}<0.001)$ and 14-years old boys $(\mathrm{p}=0.008)$ and girls $(\mathrm{p}<0.001)$. Similarly, self-perceived PSE was higher in 2017 as compared to 2000 among both 11-years old boys $(\mathrm{p}<0.001)$ and girls $(\mathrm{p}=0.023)$ and 14-years old boys $(\mathrm{p}=0.025)$ and girls $(\mathrm{p}=0.002)$.

Conclusions: Self-perceived GSE and PSE among children and adolescents aged 11 and 14 years in Southeastern Sweden were higher in 2017 as compared to 2000. These results are not in agreement with the increased psychological ill-health as being reported among children and adolescents during the last decade in Sweden.

*Corresponding author: Anders Raustorp, PhD, RPT, Department of Food and Nutrition, and Sport Science, University of Gothenburg, Gothenburg, Sweden, E-mail: anders.raustorp@gu.se Andreas Fröberg: Department of Food and Nutrition, and Sport Science, University of Gothenburg, Gothenburg, Sweden
Keywords: physical self esteem; global self esteem; time trends; psychological ill health; CY-PSPP.

\section{Introduction}

The psychological (i. e., mental) health, participation, and establishment of children and adolescents in society is increasingly perceived as one of today's major societal challenges. For example, the Swedish government's ambition that the UN Convention on the Rights of the Child will be Swedish law, as well as the establishment of sustainability goals in the framework of the UN Agenda 2030, have directed attention to the issue of psychological health among children and adolescents [1].

In Sweden, psychological ill-health among children and adolescents has increase with 100\% during the last decades [2]. Psychological ill-health includes a number of conditions with different levels of impairment; ranging from single, more or less painful anxiety/anxiety disorder to more server medical conditions such as those requiring hospitalization [2]. Among children and adolescents, the prevalence of anxiety syndrome and depression appears to have increase over time [2]. Nowadays, up to $10 \%$ of children and adolescents suffer from some kind of psychological ill-health [2], and latest reports suggest that the prevalence of psychological ill-health among children and adolescents in Sweden is high when compared to other Nordic Countries [3].

Humans have a capacity for self-awareness. According to the self-awareness theory, a large part of life is about finding self-development, self-image, identity and searchbelonging, and this might partly be done by comparing oneself with others [4]. Children and adolescents' self-awareness is much affected by peer-relationships and their belonging in different social contexts, and thus, their confidence in, and valuation of their own abilities are based on a comparison within one's social arena. Children and adolescents' social arena is generally larger than what adults are aware of; it might, for example, involve relationships on interactive computer-mediated technologies such as social 
media (Facebook, Instagram, Twitter etc.). Relationships through social media have been described as "a daily struggle to create and maintain social status among peers" with the goal "to be accepted, respected and liked" [5]. In this context, it should further be mentioned that children and adolescents themselves report status relations and relations to peers as important factors to determinate their psychological ill-health [5]. With both increased selfawareness and increased peers-comparison, there might be a greater risk that children and adolescents perceive themselves as not being "good enough" and such self-perception might result in negative feelings about one-self.

Moreover, self-esteem (SE) is understood as a valuation of the good and valuable in the description of one-self [6]. SE has been identified as an important factor in predicting responses to not only feedback and motivation but also lifestyle behaviors [7]. For example, high SE is related to health-outcomes such as emotional stability [8] lifesatisfaction [9] and lifestyle behaviors [10] among children and adolescents. On the contrary, low SE, has been connected to both overweight and obesity $(\mathrm{OW} / 0)$ [11, 12], and anxiety and depression [13]. Importantly, the strongest relationship has been reported between SE and anxiety and depression [14].

Based on a multidimensional understanding of SE, researchers $[15,16]$ have constructed the hierarchical model Global Self-Esteem (GSE). GSE is built up by the subdomains social, cognitive and physical SE (PSE). With respect PSE, Fox, and Corbin [17] developed the Physical Self-Perception Profile (PSPP). Similar to GSE, PSPP is built up by sub-domains, namely: Sport Competence (SC); Body Attractiveness (BA); Physical Strength (PS); and Physical Condition (PC) (Figure 1). The PSPP model questionnaire was initially established among adults but Whitehead [18] created a version suitable for children and adolescents, namely the Children and Youth PSPP (CY-PSPP). CY-PSPP has been found both valid and reliable for children and adolescents older than eight years of age [19].

Follow-up studies using the CY-PSPP have shown that self-perceived GSE decreased among girls with OW/O, and that these girls demonstrated higher levels of sadness and loneliness [11]. Studies from Sweden further show that selfperceived GSE, PSE, SC, BA, PS, and PC were stable at three, five and ten years follow-up (from 12-14 years to 2223 years of age) [21-23].

Based on the presumptions that the prevalence in psychological ill-health has increased during the last years, and that SE is related to health-outcomes and selfperceived GSE and PSE are stable over time, it might be interesting to compare self-perceived GSE and PSE among children and adolescents from two different occasions.

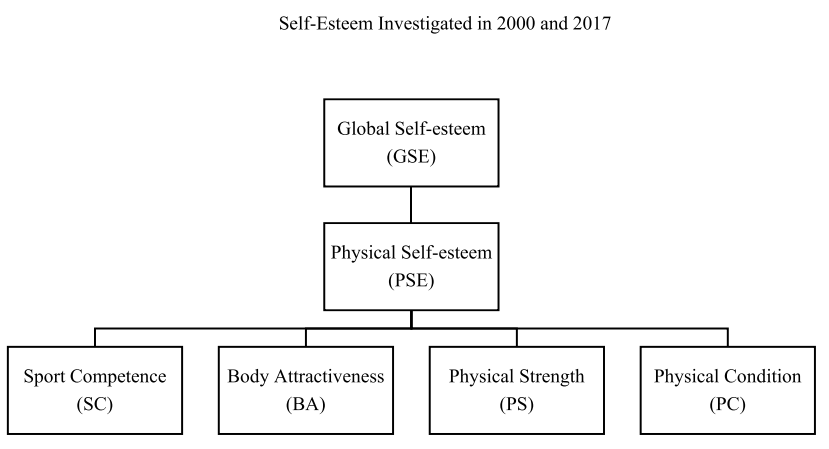

Figure 1: The hierarchal model PSPP (19).

Such comparisons involve at least two study-cohorts with children and adolescents investigated at different occasions with (some to several) years apart, sometimes referred to as "temporal-trends". Studies on temporaltrends have some underlying assumptions and/or limitations involving both sampling and measurement considerations. For example, studies on temporal-trends should compare matching populations and use similar protocols, procedures, and instruments [24].

So far, few studies on temporal-trends have compared self-perceived GSE and PSE among children and adolescents using two different study-cohorts investigated at different occasions. One study from Sweden showed higher self-perceived GSE among children and adolescents in 2008 as compared to 2000 [25]. The study further showed that self-perceived PSE remained stable during the same time-span [25]. Similar results have been presented in two studies outside Sweden [26, 27]. To the best of our knowledge, there is lack of studies comparing self-perceived GSE and PSE among children and adolescents over long timespans. Therefore, the overall aim of the present study was to compare self-perceived GSE and PSE among children and adolescents aged 11 and 14 years in Southeastern Sweden, investigated in 2000 and 2017, respectively. Given that the prevalence in psychological ill-health has increased during the last years in Sweden, our hypothesis was that there are differences in self-perceived GSE and PSE among children and adolescents aged 11 and 14 years when comparing 2000 with 2017.

\section{Participants and methods}

\section{Study design and participants}

The present study consists of two independent crosssectional study-cohorts involving children and adolescents in Southeastern Sweden, investigated in 2000 and 2017, respectively. The first study-cohort was formed in October 
2000 when data for self-perceived GSE and PSE, and anthropometry were collected from 11-years old children (Grade 5) and 14-years old adolescents (Grade 8), respectively [21]. The second study-cohort was formed in October 2017, when children and adolescents from the same gradelevels, schools and classrooms provided data for the same variables as in 2000. The participating schools were located in narrowly middle-class communities in Southeastern Sweden. Permission was sought at the community and school levels, including permission from classroom teachers in 2000 and 2017.

In total, the study-cohort in 2000 was formed by 158 participants, distributed as follows: $\mathrm{n}=74$ ( $\mathrm{n}=39$ boys) children and $n=84$ ( $n=45$ boys) adolescents. The studycohort in 2017 was formed by 326 participants, distributed as follows: $n=186$ ( $n=96$ boys) children and $n=140(n=63$ boys) adolescents. The participation rates were $91 \%$ in 2000 and 84\% in 2017. Reasons for non-participation were lack of parental permission, choosing not to participate, and absence during the day of data collection (e. g., due to illness). Participants in both study-cohorts were predominantly Caucasian which reflects the ethnic demographics in this part of Southeastern Sweden.

\section{Ethics}

Written, signed informed consent was obtained from the schools, parents, and the participants prior to data collection in 2000 and 2017. It was clarified that participation was voluntary, and that anyone could withdraw their participation at any moment without providing any further explanation or justification. The Research Ethics Committee at Linköping University approved the two data collections: 2000: DNR: 00-151; and 2017: DNR: 201-31.

\section{Instruments and procedure}

The same protocol, procedures, and instruments were used in 2000 and 2017. Self-perceived GSE and PSE were assessed with the CY-PSPP questionnaire [18]. The CYPSPP consists of 36 items representing six sub-domains with six items per domain: GSE and PSE; and sub-domains to PSE, namely SC, BA, PS, and PC. The original version of the CY-PSPP has been proven reliable and valid [27], and the CY-PSPP has been translated into Swedish and tested for reliability and validity among Swedish children and adolescents [20]. The CY-PSPP error of measurement has been reported as follows: 0.42 for SGE; 0.88 for PSE; and between 0.06 and 1.06 for the sub-domains [20].
Each of the 36 items consists of two statements which is followed by a four point structured alternative format. Firstly, the participants were asked to decide which of the two statements best describes them. Secondly, the participants were asked to decide whether the selected statement is perceived to be "kind of true" or "really true" for them. Fieldwork was performed by trained researchers who carefully described the procedure and read the two statements for each of the 36 items.

\section{Anthropometry}

In 2000, participants' body height was measured using a tape measure attached to a wall (Richter, Speichersdorf, Germany) and rounded to the nearest centimeter. Body weight was measured with step-up scales (EKS International, Wittisheim, France; HEFA Digital AB, Halmstad, Sweden) and rounded to the nearest kilogram. In 2017, similar procedures for body height and weight were performed at one of the schools. At the other four schools, however, body height and weight were measured by school nurses who were trained in anthropometry and familiar with the data gathering method. Body mass index (BMI) was calculated, and the participants were classified as being either NW or OW/O according to fullyear marking age-appropriate cut-off points [28].

\section{Data preparation and statistical analyses}

Each of the 36 items provide a score ranging from one to four, and the higher the score, the greater the selfperceived GSE, PSE, and SC, BA, PS, and PC. For each subdomain, minimum score is six points and maximum score is 24 points. Consequently, the minimum and maximum score of CY-PSPP are 36 points and 144 points, respectively.

Means $(\mathrm{M})$ and standard deviations $( \pm \mathrm{SD})$ were calculated for age, BMI, and CY-PSPP score. Statistical analyses were performed with the non-parametric Mann Whitney Utest to compare self-perceived GSE and PSE among children and adolescents, investigated in 2000 and 2017. The Mann Whitney U-test was also used to compare selfperceived PSE, SC, BA, PS, and PC among children and adolescents, investigated in 2000 and 2017. All data analyses were conducted with SPSS version 25.0 (SPSS Inc., Chicago, IL, USA) with the alpha level set at 0.05.

\section{Results}

Descriptive data for the participants is presented in Table 1. Among both 11- and 14-year olds, there were no age or BMI 
differences when comparing the two study-cohorts. In 2000 , the prevalence of children and adolescents with OW/O were 28 and $20 \%$ among 11- and 14-years old boys, respectively. The corresponding figures in 2017 were 17\% (11-years old) and 28\% (14-years old), respectively. Among girls, the prevalence with OW/O were $23 \%$ (11-years old) and 26\% (14-years old) in 2000, and 19\% (11-years old) and $20 \%$ (14-years old) in 2017, respectively.

\section{Differences in self-perceived GSE, PSE, and sub-domains}

Differences in self-perceived GSE, PSE, and sub-domains among 11- and 14-years old boys and girls are summarized in Table 1. Self-perceived GSE was higher in 2017 as compared to 2000 among both 11-years old boys ( $\mathrm{p}<0.001)$ and girls $(\mathrm{p}<0.001)$ and 14-years old boys $(\mathrm{p}=0.008)$ and girls ( $\mathrm{p}<0.001)$. Similarly, self-perceived PSE was higher in 2017 as compared to 2000 among both 11-years old boys $(\mathrm{p}<0.001)$ and girls $(\mathrm{p}=0.023)$, and 14-years old boys $(\mathrm{p}=0.025)$ and girls $(\mathrm{p}=0.002)$.

Moreover, among 11-years old boys, all sub-domains (except for PS) were higher in 2017 as compared to 2000: SC $(\mathrm{p}<0.001), B A(p<0.001)$, and PC $(p<0.001)$. Among 11-years old girls, the sub-domains SC $(\mathrm{p}=0.004)$ and BA $(\mathrm{p}<0.001)$ were higher in 2017 as compared to 2000.

Among 14-year olds, the sub-domains SC (boys $(p<0.001)$ and girls $(p<0.001))$ and PC (boys $(p<0.001)$ and girls $(\mathrm{p}=0.005))$ were higher in 2017 as compared to 2000.

\section{Differences in self-perceived GSE, PSE, and sub-domains among NW and OW/O}

Table 2 summarizes difference in self-perceived GSE, PSE, and sub-domains between 11- and 14-years old boys and girls with NW and OW/O, respectively. Among 11-years old boys, there were no differences between those with NW and OW/O (except for self-perceived PC ( $\mathrm{p}=0.012)$ ) in 2000. However, in 2017, there were differences between 11-years old boys with NW and OW/O for self-perceived PSE $(\mathrm{p}=0.010)$, BA $(\mathrm{p}=0.023)$, and PC $(\mathrm{p}=0.002)$. Moreover, among 11-years old girls, there were differences between those with NW and OW/O in self-perceived PC $(\mathrm{p}=0.008)$ and SC $(\mathrm{p}=0.004)$ in 2000. In 2017, there were differences between 11-years old girls with NW and OW/O for self-perceived GSE ( $p=0.023)$, PSE $(p=0.022)$, and BA $(p=0.000)$.

Table 1: Numbers of participants, age and BMI, as well as self-perceived GSE, PSE, SC, BA, PS, and PC among 11- and 14-years old children and adolescents, investigated in 2000 and 2017, respectively.

\begin{tabular}{|c|c|c|c|c|c|c|}
\hline & \multicolumn{3}{|r|}{ Boys } & \multicolumn{3}{|r|}{ Girls } \\
\hline & 2000 & 2017 & $\mathbf{p}$ & 2000 & 2017 & p \\
\hline \multicolumn{7}{|l|}{11 year-olds (Grade 5) } \\
\hline Number of participants & 39 & 96 & $\mathrm{n} / \mathrm{a}$ & 35 & 90 & $\mathrm{n} / \mathrm{a}$ \\
\hline Age $(y)(M \pm S D)$ & $10.98(0.32)$ & $10.92(0.34)$ & n.s. & $10.86(0.43)$ & $10.98(0.35)$ & n.s. \\
\hline $\mathrm{BMI}(\mathrm{M} \pm \mathrm{SD})$ & $19.01(3.43)$ & $17.80(3.01)$ & n.s. & $18.18(2.95)$ & $18.35(3.03)$ & n.s. \\
\hline $\mathrm{GSE}(\mathrm{M} \pm \mathrm{SD})$ & $\underline{18.00(3.26)}$ & $20.69(3.30)$ & $\leq 0.001$ & $\underline{17.05(3.18)}$ & $\underline{20.23(3.59)}$ & $\leq 0.001$ \\
\hline $\mathrm{PSE}(\mathrm{M} \pm \mathrm{SD})$ & $\underline{17.10(3.15)}$ & $20.41(3.46)$ & $\leq 0.001$ & $17.02(3.64)$ & $18.84(3.59)$ & $\underline{0.023}$ \\
\hline$S C(M \pm S D)$ & $16.51(2.73)$ & $19.33(3.40)$ & $\overline{<0.001}$ & $16.11(3.13)$ & $\overline{18.06(3.33)}$ & $\overline{0.004}$ \\
\hline $\mathrm{BA}(\mathrm{M} \pm \mathrm{SD})$ & $\overline{15.71(3.11)}$ & $\overline{18.17(3.56)}$ & $\overline{<0.001}$ & $\overline{14.82(3.89)}$ & $\overline{18.14(3.94)}$ & $<\overline{0.001}$ \\
\hline$P S(M \pm S D)$ & $\overline{17.43(3.72)}$ & $\overline{18.69(3.89)}$ & $\overline{\text { n.s. }}$ & $\overline{16.37(3.20)}$ & $\overline{16.72(3.83)}$ & n.s. \\
\hline$P C(M \pm S D)$ & $16.58(3.29)$ & $19.51(4.28)$ & $\leq 0.001$ & $16.80(3.43)$ & $17.85(3.49)$ & n.s. \\
\hline \multicolumn{7}{|l|}{14 year-olds (Grade 8 ) } \\
\hline Number of participants & 45 & 63 & $\mathrm{n} / \mathrm{a}$ & 39 & 77 & $\mathrm{n} / \mathrm{a}$ \\
\hline Age $(y)(M \pm S D)$ & $13.84(0.36)$ & $13.83(0.42)$ & n.s. & $13.79(0.40)$ & $13.78(0.44)$ & n.s. \\
\hline $\mathrm{BMI}(\mathrm{M} \pm \mathrm{SD})$ & $19.95(3.19)$ & 21.10 & n.s. & $21.02(2.88)$ & $20.55(2.71)$ & n.s. \\
\hline $\mathrm{GSE}(\mathrm{M} \pm \mathrm{SD})$ & $\underline{16.51(3.09)}$ & $\underline{18.49(4.05)}$ & $\underline{0.008}$ & $14.66(3.70)$ & $17.74(4.88)$ & $\leq 0.001$ \\
\hline $\mathrm{PSE}(\mathrm{M} \pm \mathrm{SD})$ & $\overline{15.88(2.90)}$ & $\overline{17.68(4.37)}$ & $\overline{0.025}$ & $13.92(2.79)$ & $16.28(4.22)$ & 0.002 \\
\hline $\mathrm{SC}(\mathrm{M} \pm \mathrm{SD})$ & $15.15(2.80)$ & $17.93(3.64)$ & $\overline{0.001}$ & $14.00(3.02)$ & $\overline{16.22(4.19)}$ & $\overline{0.005}$ \\
\hline $\mathrm{BA}(\mathrm{M} \pm \mathrm{SD})$ & $\overline{14.91(2.84)}$ & $\overline{16.12(4.12)}$ & $\overline{\text { n.s. }}$ & $\overline{13.25(3.15)}$ & $\overline{14.75(4.47)}$ & n.s. \\
\hline$P S(M \pm S D)$ & $15.48(3.15)$ & $16.38(4.51)$ & n.s. & $13.74(3.37)$ & $14.32(3.76)$ & n.s. \\
\hline$P C(M \pm S D)$ & $\underline{15.51(3.19)}$ & $18.20(3.95)$ & $\underline{0.001}$ & $13.51(3.16)$ & $17.29(3.79)$ & $<0.001$ \\
\hline
\end{tabular}

Abbreviations: BA, Body attractiveness; BMI, Body mass index; GSE, Global self-esteem; PC, Physical condition; PSE, Physical self-esteem; PS, Physical Strength; SC, Sport competence.

Significant results highlighted in underlined. 
Among 14-year-olds, there were no differences between those with NW and OW/O neither for selfperceived GSE and PSE, nor SC, BA, PS, or PC in both 2000 and 2017.

\section{Discussion}

The main finding of this study was that both self-perceived GSE and PSE among children and adolescents aged 11 and 14 years were higher in Southeast Sweden in 2017 as compared to 2000. Overall, both self-perceived GSE and PSE exceed the error of measurement for the CY-PSPP with margin.

The increase in prevalence of psychological ill-health among children and adolescents in Sweden is based on medical diagnoses established through contact with the health-care system. Partly, such increase may be due to the fact that psychological ill-health nowadays is less stigmatized; therefore, it might be expected that today's children and adolescents are more prepared and willing to establish a contact with the health-care system than 17 years ago. However, given the observed increase in anxiety and depression rate, among children and adolescents in later years [2], were self-perceived GSE are reported to influence [14], we expected that selfperceived GSE and PSE would be lower in 2017 as compared to 2000. Interestingly, we appear to have found the opposite, and our hypothesis that there were differences in self-perceived GSE and PSE among children and adolescents aged 11 and 4 years when comparing 2000 with 2017 was not confirmed.

The environment in which children and adolescents live their everyday life is in some important ways fundamentally different in 2017 as compared with 2000. For example, the use of smartphones, computerized tablets and social media has increased during the latest 17 years. For example, since 2010, Internet usage on smartphones and computerized tablets among children and adolescents has increased dramatically [30]. Studies show some deleterious health-effects of interactive computer-mediated technologies such as social media. For example, social media might be used for so-called cyber-bullying which may negatively influence psychological ill-health [31]. In addition, studies have shown that social media such as Facebook and Instagram might negatively influence body image among children and adolescents. Altogether, this may indicate that the self-perceived GSE and PSE would have been lower in 2017 as compared to 2000. As mentioned previously, the self-awareness theory suggests that a large part of life is about finding self-development, self-image, identity and search-belonging. Because this is partly done by comparing one-self with others, our findings might indicate that social media might be a social arena that some children and adolescents uses to facilitate searchbelonging which may facilitate higher self-perceived GSE and PSE.

Furthermore, differences in self-perceived PSE and BA were observed between 11-years old boys with NW and OW/O in the 2017 study-cohort. Such differences were not observed in 2000. These findings might indicate that both body-image and feeling of being successful in, for example, organized sports are influenced at early ages among boys with OW/O. Further, difference between 11-years old boys with NW and OW/O was observed in terms of self-perceived PC in both 2000 and 2017. Interestingly, however, no difference in self-perceived GSE and PSE were observed between 14-year olds with NW and OW/O (boys and girls) and we have no reasonable explanation for these findings.

Possible explanation for these somewhat positive findings might be the drop-out; although we had reasonable high response rate in both 2000 (91\%) and 2017 (84\%), there is a possibility that those who did not participate differed in some important aspects such as BMI-level and/or self-perceived GSE and PSE. However, the percentage of children and adolescents with OW/O - a wellestablished risk-factor for developing psychological ill-health - in the 2017 study-cohort appear to be similar as national levels (21\%) [29] except for 14-years old boys where the figure was slightly higher. However, even in this particularly group, we found higher self-perceived GSE and PSE in 2017 as compared to 2000, and no difference were observed between children and adolescents with NW and OW/O.

\section{Strengths and limitations}

The present study has both strengths and limitations. Strengths include the study-design and the usage of the same protocol, procedures, and instruments in 2000 and 2017. More specifically, data was collected during the same month (i. e., October) in 2000 and 2017; and the two independent study-cohorts of children and adolescents were included from the very same schools and classroom, who used the same schoolyard at both occasions. In addition, the children and adolescents included from the 2000 and 2017 studycohorts may have used similar ways of commuting to/from the school, and they likely live in similar neighborhoods. Thus, factors such as the socio-economic conditions might have been similar in 2000 and 2017.

In terms of limitations, it is emphasized that the two cross-sectional study-cohorts were recruited from narrowly 


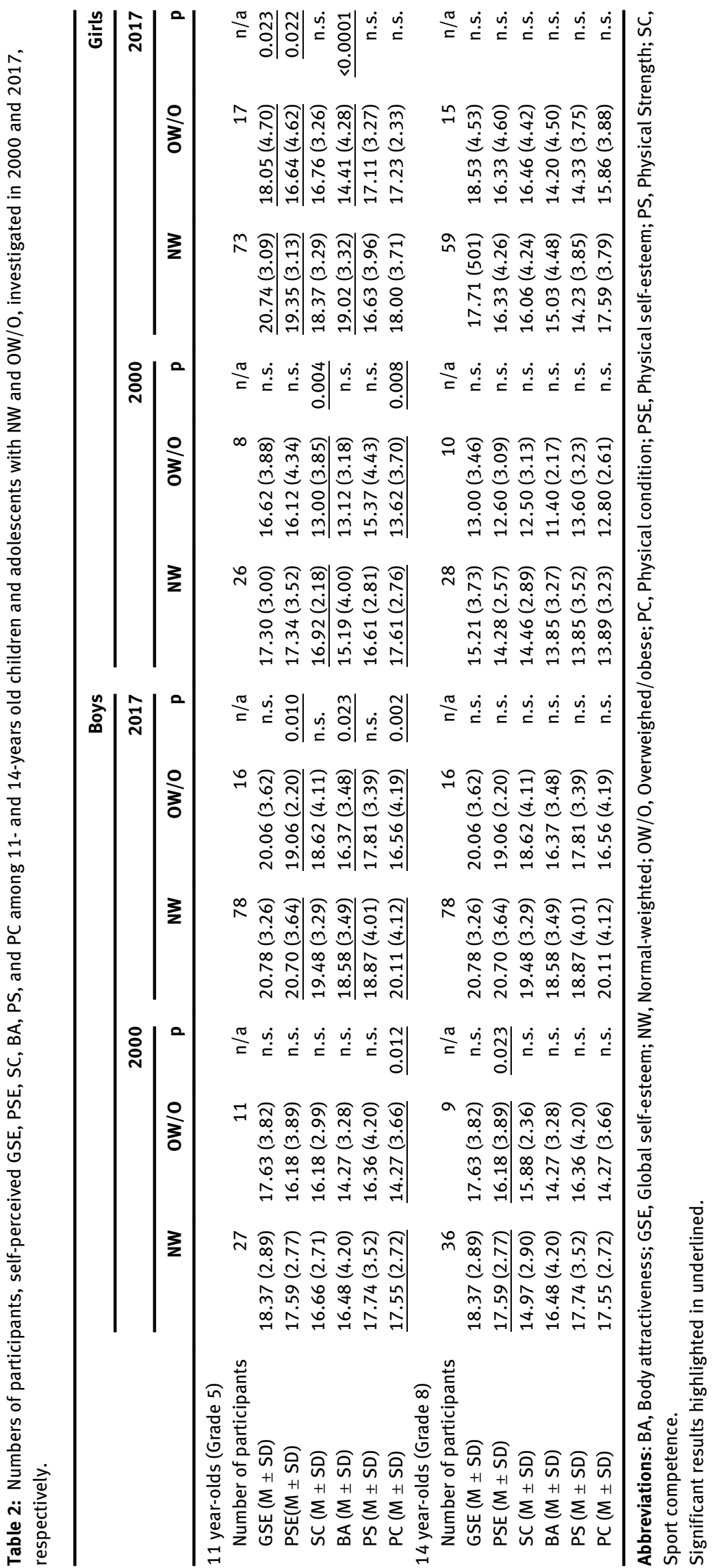


middle-class communities in Southeastern Sweden. As a consequence, caution is required when interpreting the results as these might not be generalizable to children and adolescents across Sweden as a whole. Further, we lack information regarding the children and adolescents who did not participate due to, for example, lack of parental permission, choosing not to participate, and absence during the days of data collection, and this is acknowledged as a limitation. Further, it is also important to stress that that the interpretation of the 36 items in the CY-PSPP (i. e., in a semantic manner) might have different meanings and value to children and adolescents in today's society as compared to 17 years ago. Cautiousness is also warranted when interpreting differences for self-perceived GSE, PSE and subdomains between children and adolescents with $\mathrm{NW}$ and $\mathrm{OW} / \mathrm{O}$ as the prevalence of $\mathrm{OW} / \mathrm{O}$ was low in the present study.

\section{Conclusions}

In conclusion, self-perceived GSE and PSE among children and adolescents aged 11 and 14 years in Southeastern Sweden were higher in 2017 as compared to 2000. These results are not in agreement with the increased psychological ill-health as being reported among children and adolescents during the last decade in Sweden.

Acknowledgments: We thank the participating schools and school-children. This research was funded by the Swedish Research Council for Sport Science, the STINT Teaching Excellence Grant, the Swedish Heart and Lung Foundation, and Kempe Carlgrenska-stiftelsen.

Author contributions: Design; AR, Data gathering; AR, AF, Data analysis, writing manuscript; AR, AF.

Competing interest: No competing interests to report.

Informed consent: This information is provided under Ethics "Written, signed informed consent was obtained from the schools, parents, and the participants prior to data collection in 2000 and 2017. It was clarified that participation was voluntary, and that anyone could withdraw their participation at any moment without providing any further explanation or justification.

\section{References}

1. UN (United Nations General Assembly). Transforming our world: the 2030 agenda for sustainable development A/RES/70/1. 2015. Available from: http://www.un.org/ga/search/view_doc.asp? symbol=A/RES/70/1\&Lang $=E$.
2. Socialstyrelsen. (National Board of Health and Welfare). Utvecklingen av psykisk ohälsa bland barn och unga vuxna. Fram till 2016. Artikelnr 2017-12-27. 2017. Available from: https:// www.socialstyrelsen.se.

3. World Health Organization (WHO). Health behaviour in schoolaged children (International report from the 2013/2014 survey). Europe: WHO Regional Office for Europe, Copenhagen; 2016.

4. Duval S, Wicklund RA. A theory of objective self-awareness. Oxford, UK: Academic Press; 1972.

5. Hiltunen L. The pursuit of restrained perfection: experiences of ill health among adolescent girls and boys. (In Swedish; Lagom perfekt. Erfarenheter av ohälsa bland unga tjejer och killar) [Thesis], Växjö, Sweden: Linnaeus University; 2017.

6. Whitehead JR. A study of children's physical self-perceptions using an adapted physical self-perception profile questionnaire. Pediatr Exerc Sci 1995;7:132-51.

7. Kernis MH, Cornell DP, Sun SR, Berry A, Harlow T. There is more to self-esteem whether it is high or low: the importance of stability of self-esteem. J Pers Soc Psychol 1993;65:1190-204.

8. Sonstrom RJ. The physical self-esteem: a mediator of exercise and self-esteem. In Fox KR, editor. The physical self. From motivation to well-being. Champaign, IL: Human Kinetics; 1997: $20 \mathrm{p}$.

9. Diener E, Diener M. Cross-cultural correlates of life satisfaction and self-esteem. J Pers Soc Psychol 1995;68:653-63.

10. Torres R, Fernandez F. Self-esteem and the value of health as determinants of adolescents health behaviour. J Adolesc Health Care 1995;16:60-3.

11. Strauss, R.S. Childhood obesity and self-esteem. Pediatrics 2000;105:e15.

12. Rasmussen F, Eriksson M, Bokedal C, Schäfer Elinder L. Community-based study of physical activity, life style and selfesteem in Swedish school children. Rapport 2004;1 Stockholm (In Swedish).

13. Baumeister RF. Understanding the inner nature of self-esteem. In Baumeister RF, editor. Self-esteem: the puzzle of low self-regard New York: Plenum Press; 1993:201-8 pp.

14. Orth U, Robins RW, Roberts BW. Low self-esteem prospectively predicts depression in adolescence and young adulthood. J Personality Soc Psych 2008;95:695-708.

15. Shavelson RJ, Hubner JJ, Stanton GC. Self-concept: Validation of construct interpretations. Rev Educ Res 1976 46; 407-41.

16. Harter S. Manual for the self-perception profile for children. Denver, CO: University of Denver; 1985.

17. Fox KR, Corbin CB. The physical self-perception profile: Development and preliminary validation. J Sport Exerc Psych 1989;11:408-30.

18. Whitehead JR. A study of children's physical self-perceptions using an adapted physical self-perception profile questionnaire. Pediatr Exerc Sci 1995;7:132-51.

19. Welk GJ, Eklund B. Validation of the children and youth physical self-perception profile for young children. Psych Sport Exerc 2005;6:51-65.

20. Raustorp A, Stahle A, Gudasic H, Kinnunen A, Mattsson E. Physical activity and self-perception in school children assessed with the children and youth physical self-perception profile. Scand. J Med Sci Sports 2005;15:126-34.

21. Raustorp A, Mattsson E, Svensson K, Stahle A. Physical activity, body composition, and physical self-esteem-a three year follow- 
up study among adolescents in Sweden. Scand J Med Sci Sports 2006;16:258-66.

22. Raustorp A, Archer T, Svensson K, Perlinger T, Alriksson M. Physical self-esteem - a five year follow-up study on Swedish adolescents. Int J Adolesc Med Health 2009;21: 497-507.

23. Raustorp A, Lindwall M. Physical self-esteem - a ten-year follow-up study from early adolescence to early adulthood. Int J Adolesc Med Health 2015; 27:31-9.

24. Malina RM. Physical fitness of children and adolescents in the United States: status and secular change. Med Sports Sci 2007; 50:67-90.

25. Raustorp A. Eight year's secular trends of perceived physical selfesteem in Swedish young adolescents. Int J Adolesc Med Health 2010;22:237-47.

26. Raudsepp L, Kais K, Hannus A. Stability of physical selfperceptions during early adolescence. Pediatr Exerc Sci 2004;16: 138-46.
27. Morgan CF, Graser SV, Pangrazi RP. A prospective study of pedometer-determined physical activity and physical self-perceptions in children. Res Q Exerc Sports 2008;79:133-40.

28. Cole TJ, Nicholls D, Jackson AA, Flegal KM. Establishing a standard definition for child overweight and obesity worldwide: international survey. BMJ 2000;320:1-6.

29. Warensjö Lemming E, Moraeus L, Petrelius Sipinen J, Lindroos AK. Riksmaten Ungdom 2016-17. Livsmedelskonsumtion bland ungdomar i Sverige. (Riksmaten adolescents 2016-17 Food consumption in adolescents in Sweden). Uppsala Sweden: Livsmedelsverket 2018.

30. Swedish Media Council (Statens Medierad). Kids \& media 2017 (Ungar och media) (cited 2018 August 27). Available from: https://statensmedierad.se/publikationer/ungarochmedier/ ungarmedier2017.2344.html.

31. Aboujaoude E, Savage MG, Starcevic V, Salame WO. Cyberbullying: review of an old problem gone viral. J Adolesc Health 2015;57:10-8. 